International Journal of English Literature and Social Sciences
Vol-7, Issue-1; Jan-Feb, 2022
Journal Home Page Available: https://ijels.com/
Journal DOI: $10.22161 /$ ijels

Peer-Reviewed Journal

\title{
A Theoretical Review: Sociolinguistics in Second Language Education
}

\author{
Dr. K. Sankar
}

Assistant Professor of English, Dr. N.G.P. Arts and Science College (Autonomous), Coimbatore, India meetsancks@gmail.com

Received: 09 Dec 2021; Received in revised form: 22 Jan 2022; Accepted: 04 Feb 2022; Available online: 10 Feb 2022 (c)2022 The Author(s). Published by Infogain Publication. This is an open access article under the CC BY license (https://creativecommons.org/licenses/by/4.0/).

\begin{abstract}
Divergent thoughts are always explored in education from time to time, with a view to building a better society and economy. Time to time, many renovations take place in educational policy and system, yet medium of instruction likely remains same because language is the key channel through which education, culture and social inclination are also imparted. No doubt, language is the primary mode to engage human activities similarly it educates about the social setup and needs. The culture of a society always is reflected through language and respectively language reveals the particular society's culture and custom. Therefore, the term sociolinguistics is coined under language study. The students consider the second language learning is a paper in their selected discipline, they never see L2 is as language learning. The formal language education gives good knowledge on language and linguistics, but the students involve in real-life they face lot of challenges to communicate or understand the social need. There is a gap between society and formal language education, because the classroom exposure alone is not enough to develop one's language efficacy. The existing language syllabus for L2 is likely based on the four skills and there is no inclusion of pragmatics and sociolinguistics aspects in it. Education should go with the social order and state of affairs. The present paper attempts to study the possible insights on sociolinguistics with relevant to the existing $L 2$ education.
\end{abstract}

Keywords - Linguistics, Sociolinguistics, Second language, Acquisition, Theory.

\section{INTRODUCTION}

Language is the prime medium for human activities which develop man's ability and knowledge in language that helps human to develop their cognitive skills in different aspects. Samir K. Ghosh aptly says: 'Experience of language realized through social determinants of nature, variability, and dependence will contribute to a direct connection between knowledge about the language and knowledge' (260). Languages are different in terms of their nature and use but they have been mainly used for day-to-day communication. Similarly in every language, time to time many modifications and formation of new words gradually happen, and that have to be taught in the language classroom, because language and society are strongly interlinked. Relevant to this point, George Yule aptly writes, 'It is a feature of all languages that novel utterances are continually being created. A child learning language is especially active in forming and producing utterances which he or she has never heard before. With adults, new situations arise or new objects have to be described, so the language-users manipulate their linguistic resources to produce new expressions and new sentences' (23).

Language education ought to be focused on respective local needs and cultural aspects, because the formal language teaching and learning give students with only formal learning exposure, when they come to society, they face many issues in their communication. Through formal language learning the students will get good autonomy in L1 or L2, but in real-life the use of language will be different to use of the same with formal learning. A good understanding of a society and its culture describes 
about the pragmatics. Moreover, simply studying any language will not give proficiency, until thoroughly understand the particular society and its culture. In view of this, George Yule expresses: '... sociolinguistics deals with the inter-relationship between language and society. It has strong connections to anthropology, through the investigation of language and culture, and to sociology, through the crucial role that language plays in the organizations of social groups and institutions' (239). Language deals with communication channels within individuals and a social order. The field of Sociolinguistic is aimed to relate the utility of language and how it is affected by class, gender, race with respect to social phenomenon.

Sociolinguistics is a distinctive field of study was developed during $20^{\text {th }}$ century, and the term 'Sociolinguistics' was first used in linguistics by Eugene Nida in his second edition of Morphology (1949). Many of linguists and educationists stated that Sociolinguistics is an important part of the language field which describes the pragmatics and contextual state of affairs. Miriam Meyerhoff defines: 'Sociolinguistics is a very broad field, and it can be used to describe many different ways of studying language' (1). The field of Sociolinguistics initially was become known during 1960s and was pioneered by linguists such as Basil Bernstein in U.K. and William Labov in U.S. Bernstein's 'code theory' and Labov's 'variability concept', are resulted in innovative methodological tools and theoretical as well as practical insights in Sociolinguistics. Basil Bernstein is well known in the study of Sociolinguistics and his theory of language codes examined the relationships between social class, family and the reproduction of meaning. Moreover, it makes better understanding of the nature of the relationship between language and society. Accordingly, Peter Trudgill rightly defines Sociolinguistics as: ' ... is that part of linguistics which is concerned with language as a social and cultural phenomenon. It investigates the field of language and society and has close connections with the social sciences, especially social psychology, anthropology, human geography and sociology'

(32). Thus, in many aspects it is proven that the language and society are strongly connected and respectively language details the culture in different contexts and culture is witnessed through language as well.

\section{LANGUAGE AND CULTURE}

Since every language is concerned as medium, it communicates the message or information from one to another. Any culture can be seen through the nature of society, but all the time it is not possible. If anyone wants to learn any particular culture, it is possible through literature. Sociology describes the relationship between human and society, the categorization of race, beliefs and common culture, and social constancy. Clarie Kramsch aptly quotes: 'The first insight relates to culture as semantically encoded in the language itself; the second concerns culture as expressed through the actual use of the language' (14). A society time to time faces evolutions accordingly it can be found new features in the language, because both are not static. Hence, language is in a constant state of change until it has ceased to be spoken or has become a dead language.

In any culture, there can be many changes according to its developments that certainly reflect in the society and language respectively. Since language and culture are always not constant, it is necessary to update the changes accordingly in the language policy. Relevant to this fact Nancy H. Hornberger, and Dr. Sandra Lee McKay aptly comment: 'Popular culture is also not an easy object to study in itself. Unlike less popular forms of culture, it does not stay still for very long. This is an issue both for research and for a pedagogical engagement with popular culture, since what is popular today may not be so tomorrow' (79). Corresponding to the point either the first or second language should be taught relevant to present phenomenon and prerequisites of the learners. Moreover, the learners ought to learn the pragmatics of the respective society that only makes them convenient when they meet real life situation. Formal learning may help learners in basic but they cannot always communicate all through the basics. Because the function of language in a society is different from the classroom learning, to overcome this issue the pragmatics and the aspects of sociolinguistics should be inculcated in the language classroom itself.

In day-to-day communications everyone can see social and cultural roles hence these processes are so deeply entrenched in their life that cannot be always noticed. Language cannot be separated from customs that are from the communally innate behaviours and beliefs which determine the consistency of human's life. George Yule says: 'language is passed on from one generation to the next is described as cultural transmission. While it has been argued that humans are born with an innate predisposition to acquire language' (24). Likewise, ethnicity and language are indivisible because culture not only states who talks to whom and how the communication happens, further it facilitates to find out how speakers encode the message, the meanings they indented, the 
circumstances under which various information possibly be sent or interpreted, subsequently culture becomes the foundation for communication.

\section{LANGUAGE AND SOCIETY}

Language plays inevitable roles in a society and the relationship either is widely rooted. Every social change makes changes in language which incorporate the social values within its parameter. Similarly language and society have a mutual association: language determines the social interactions and social relations build the language. Sociolinguistics studies the effect of society in cultural norms, and divergent contexts, the way language is used and the effect of language on society. Relevant to this point George Yule comments: 'It is important not to overlook this social aspect of language because, in many ways, speech is a form of social identity and is used, consciously or unconsciously, to indicate membership of differ social group or different speech communities. A speech community is a group of people who share a set of norms, rule and expectations regarding the use of language' (239).

To study the human society without language is very hard and without society is no means of evaluating the history of any language. The Interactionist sociolinguistics is principally interested in what language use can state about social processes and therefore a central concern is the social meaning of language use. Mc Iver and Charles observe: 'Man's relation with the society is so intimate and close that it is very difficult to isolate him from the environment in which he is born, nurtured and grown to be a man' (45). Language is central to one's identity as an individual and as a marker of a social group. The use of a particular language variety indentifies as everyone belongs to a particular social group. It is the flesh and blood of a human culture. David Crystal has expressed: 'Language is the repository of the history of a people. It is their identity. Oral testimony, in the form of sagas, folktales, songs, rituals, proverbs and many other practices, provides us with a unique view of our world and a unique canon of literature' (20).

The American linguist William Labov is wellknown for quantitative Sociolinguistics, which mainly concerns on the study of language variation and change. Further his difference hypothesis aimed at the explanation of all linguistic variations caused by the involvement of social factors. His study illustrates the relevance of social determinants of linguistic variations and their correlations with the social structure. Correspondingly, he recommended a social approach to language through his sociolinguistic model in which the linguistic theorization is linked with the society. In this view R.A. Hudson defines: 'Since speech is (obviously) social behaviour, to study it without reference to society would be like studying courtship behaviour without relating the behaviour of one partner to that of another' (3). According to their views language has been classified as vernacular, dialect, idiolect, discourse, register, sociolect, slang, topolect or regional dialect. So, while framing curriculum for language it is necessary to integrate the features into curriculum.

The use of a particular language variety shows each of us as belonging to different social group. Language like society is constantly evolving and is subject to growth and change in much the same way as a living organism. There are some possible associations between language and society. A social structure may either influence or determine linguistic structure and/or behaviour. It is also seen that particular ways of speaking, choice of words, and even rules for conversing are in fact highly determined by certain social requirements. Relevant to this point Bernard Spolsky writes: 'Just as the formal linguist and the psycholinguist focus their attention on the language as a system with universal features, so the sociolinguist looks at the complex connections between the variations within a language and the matching variations in the social groups that use it' (5). Language constitutes of both linguistic and communicative competence.

Sociolinguists differentiate a set of types of variation that covers most factors for language variation. The most general distinction is that between variation in the individual, so called idiolects, variation related to social factors, sociolect, regional variation, dialects and variation due to functional aspects, so called registers or styles. George Yule aptly says: "Variation according to the gender of the speaker has been the subject of a lot of recent research. One general conclusion from dialect surveys is that female speakers tend to use more prestigious forms than male speakers with the same general social background' (242). Sociolinguists are more interested in studying social variation in language than regional variation. However, to understand various procedures used in the studies of social variation in language grew out of studies of regional variation.

David Crystal exactly says: 'language is the repository of the history of a people. It is their identity. Oral testimony, in the form of sagas, folktales, songs, rituals. Proverbs, and many other practices, provides us with a unique view of our world and a unique canon of literature' (20). Language itself is a mirror of society. The values of society can be reflected in its language. One way in which this happens is through taboo words. Elaine 
Chaika states: 'Language and society are so intertwined that it is impossible to understand the one without the other. There is no human society that does not depend upon, is not shaped by, and does not itself shape language' (2). Taboo is concerned with behaviour which is supernaturally forbidden, or regarded as immoral or improper. In language taboo words refer to words not said or not used. Every language has taboo words and if the particular rules in par with taboo words are not adhered to, it can lead to punishment or public shame. In fact, taboo words reflect the values and beliefs of a particular society.

\section{LANGUAGE AND EDUCATION}

As language is primary and mandate for communication, language in educational set-up it plays vital role in developing the students' thoughts and knowledge. In the same way, the educational programmes and policies often emphasize curriculum and instruction to facilitate language learning. Learning in classroom is primarily accomplished through language and culture of respective society. Since language and culture have a great influence each other. In view of this Nancy H. Hornberger and SandraLee McKay write: 'in many ways, the relationship between language and culture plays a key role in education. Classrooms across the world are increasingly populated by students and teachers of diverse language and cultural backgrounds' (455). Other than native language use has become a major trend around the world. People begin to learn a foreign language to seek abroad education, international business and for their journey. Therefore, the second and foreign language education becomes magnificent. Broadly speaking, foreign language teaching has two goals. First it is to strengthen the classroom accessibilities and the students learn the formal properties with reference to their local need and contextual purpose.

Language teaching is the process of transforming the language with the phenomenon by the teacher to learners and in which it is to be obtained all aspects of language. It may explain all facets of language such as social, cultural, lexicon, syntax, etc. Language teaching related to society and culture are studied in sociolinguistic. Relevant to this view George Yule depicts: 'within the definition of culture as 'socially acquired knowledge'. Given the process of cultural transmission by which languages are acquired' (246). It dissects the language related to their masculinity and ethnicity; therefore, the language users can apply it with appropriate way. To understand and promote learning, it is not only included teachers but also peers and others, such as administrators and people in the outside community.
The teachers tend to teach it mostly relate to how the students able to use grammar and words, local society, not the target language society, therefore, the students more focus on how to arrange the words/sentences to be a good sentence/paragraph and speak with local accent that sometimes unacceptable of the second or third language. Related to language teaching, the teacher should consider the individual factors of learners three of them are age, social and educational context. During the mid of twentieth century, language education and its policies were improvised by implementing the new methods and approaches to implicate the aspects of linguistics, cognition and sociolinguistics to the task of developing proficiency in L2. With human evolution the need for language and communication became evident. It became almost like an organic need. Communication is necessary and vital to man just like the intake of water and food is essential for survival of mankind.

\section{LINGUISTICS AND SOCIOLINGUISTICS}

Sociolinguistics is introduced by Peter Trudgill (1995) and it is accepted as sub-discipline under linguistics. It is regarded as novel discipline hence it deals with a relationship that had been neglected in the past linguistic studies i.e. the relationship between language and society. Since the development of the discipline Sociolinguistics, the argument between linguists has centred on whether language should be studied as a closed or as an open system. On the other side, theoretical linguists perceive language as a closed system that should be studied for its own sake. For them, emphasis should be put on studying the underlying structure of the linguistic system and the concern of the theoretical linguist is to devise a theory of grammar.

With respect to above aspects the differences between speakers have to be overlooked. Relevant to this issue, Chomsky (1965) says: 'Linguistic theory is concerned primarily with an ideal speaker-listener in a completely homogeneous speech community, who knows its language perfectly and is unaffected, by such grammatically irrelevant conditions as memory limitations, distractions, shifts of attention and interest, and errors' (3). Sociolinguistics discipline is a new perspective of study in language and it is an open system interacts with a variety of factors. According to R.A. Hudson (1996): 'Since speech is (obviously) social behaviour, to study it without reference to society would be like studying courtship behaviour without relating the behaviour of one partner to that of another' (3).

Hudson believes that there is a close connection between language and society because one cannot 
segregate language from society. He is of the opinion that language should be studied in the cultural context. The users of language come from various social classes. Therefore, their language is influenced by the social norms and cultural patterns. Theoretical linguists recognize the relationship between language and society. They just ignore it to have a deeper insight into the system itself, and their concentration on competence was 'a necessary simplification that led to several theoretical advances' (Trudgill, 20).

Sociolinguistics recognize the importance of studying language as a system, as Saville-Troike (2003) stated introducing the ethnography of communication, the ethnography of communication takes language first and foremost background of both the addresser and the addressee, ethnic background and the context and communication. The social background of the both the speaker and listener and social class education, geographic origin, background, gender and age are necessary factors to be studied to know the language of the speakers. In view of this, an attempt is made to throw light on the present study to recognize the distinctive features of mentioned factors.

\section{SOCIOLINGUISTICS AND LANGUAGE EDUCATION}

Different social factors affect language teaching and language learning. The present research paper examines the affiliations between sociolinguistics and language use. Further the paper explores the main aspects which influence linguistic choices and explains how contemporary teaching is helpful to the learners. George Yule writes: 'The notion that language determines thought may be partially correct, in some extremely limited way, but it fails to take into account the fact that users of a language do not inherit a fixed set of patterns to use. They inherit the ability to manipulate and create with a language, in order to express their perceptions. If thinking and perception were totally determined by language, then the concept of language change would be impossible' (248). In L2 classroom the teachers often disregard the sociolinguistics aspects and they mainly focus to teach the contents prescribed in the syllabus. So, the students fail to understand the pragmatics. Therefore, the teacher should associate the L2 learners' activities with social contexts.

\section{SOCIOLINGUISTICS CONCEPTS AND THEORIES}

The field of Sociolinguistics is mainly focused on to study on pragmatics. Holmes defines Sociolinguistics as the study of 'the relationship between language and society' (1). It is an interdisciplinary area of research strongly associated with culture through the study of language and sociology. Sociolinguistics is a broad area of research hence it is important to learn what Sociolinguistics is. There are number of linguists who defined Sociolinguistics relevant to their understating and research: according to Spolsky (2010) 'Sociolinguistics is the study of the link between language and society, of language variation, and of attitudes about language', Hudson (1996) 'a study of the relationship between language and social factors such as class, age, gender and ethnicity', and Bell (1976) 'a branch of anthropological linguistics that examines how language and culture are related, and how language is used in different social contexts'.

Fishman defined sociolinguistics as the study of varieties, function, and speaker of the language. According to him, they are changeable, interacting, and modification in language society. According to Grimperz (1971), there are four kinds relationship between language and society as follows (1) language determine society; (2) sociocultural determine language; (3) co-variance between social facts and language; (4) language and society is determined by other factors such as culture, abstract structure or biological nature. Sociolinguistics is a discipline that links sociology with linguistics, and it focuses on language use like when, where and how. The different sociolinguists opined in various aspects for a better understanding of sociolinguistics. Gumperz (1971) has observed: 'Sociolinguistics is an attempt to find correlations between social structure and linguistic structure and to observe any changes that occur' (223).

Peter Trudgill emphasized that the sociolinguistic research helps in getting a better understanding of the nature of human language by studying language in its social context. It also provides a better understanding of the nature of the relationship between language and society. He further defines Sociolinguistics as: 'Sociolinguistics... is that part of linguistics which is concerned with language as a social and cultural phenomenon. It investigates the field of language and society and has close connections with the social sciences, especially social psychology, anthropology, human geography and sociology' (32). These are also areas most susceptible to scientific methods such as hypothesis formation, logical inference, and statistical testing. The above definitions by the expert sociolinguists indicate that Sociolinguistics is known as a branch of study that 
assumes that human society is made up of many related patterns and behaviours.

\section{MODERN PERSPECTIVES}

Sociolinguistics has become a mandate field of study in language education and research and everyone awakes the role of language not just as a means of communication, but also a creator of social identity. Sociolinguistics is an interesting area of language for teachers becauselit deals with how the language is used and thought of in the real world. When teaching English, it is therefore critical to ignore any kinds of intolerance of class differentiation toward the existing culture of the child and English culture. The notion of upper-class language or more prestigious language derived from several aspects which Kloss (1966) has categorized to rich heritage, high degree of language modernization, considerable international standing, or the prestige of its speakers. Once English was taught and learned for social interaction and business, but now the condition is in inverse; for higher education it is mandatory, most of the business communication happens via English, becomes corpus language, speaking in English is respected and prestigious.

The study of language and linguistics has been classified into divergent contexts and divisions, correspondingly number of researchers are initiated. With a view to aggrandizing the second language competences, there are lots of methods and approaches have been founded. Richards and Rodgers rightly comment: 'the history of language teaching in the last one hundred years has been characterized by a search for more effective ways of teaching second or foreign languages. The commonest solution to the "language teaching problem" was seen to lie the adoption of a new teaching approach or method' (244). Therefore, it is needed good initiations by researchers, governments and academies.

Language learning and teaching become technology based, elevating the traditional setup to present milieu, respective governments have to revise the language education policies, and grant fund for improving the traditional classroom into technology based. Language teaching shall be done with individual interest and great desire. Richards and Rodgers aptly suggest: 'Teaching has sometimes been described as artistry rather than science and is often shaped by the influence of powerful individual practitioners with their own schools of thought and Followers' (253). Also, it is required good research and projects to face the current impedimenta in language teaching and learning. Despite different motif in language education there are number of possible scopes available while considering the rapid growth of science and technology.

\section{CONCLUSION}

Since sociolinguistic is the study about the relationship between language and society, language variation, and attitudes of language. It is supported by Hudson defined as a study of the relationship between language and social factors such as class, age, gender and ethnicity. Whereas Bell said it is a branch of anthropological linguistics that examines how language and culture are related, and how language is used in different social contexts. The study of stylistic and social variation of language and the study of language in relation to its social-cultural contexts. Sociolinguistics is the study of the effect of any and all aspects of society, including cultural norms, expectations, and context on the way language is used. Understanding the features of sociolinguistics, the theory of language acquisition and pragmatics it clearly enumerates that society and language are not different rather both make greater impact in language education. Especially in second language education the discussed factors in the paper ought to be taken consideration wile framing policy, curriculum and syllabus in the future. Language education should be more relevant to sociological aspects that will make the students face communication barriers easily and understand them. Finally, I express my heartfelt thanks to my colleagues and my institution for their great support in completion of this research paper.

\section{REFERENCES}

[1] Chaika, E. (1989), Language the Social Mirror. New York: Newbury House Publisher.

[2] Chomsky, N. (1965), Aspects of the Theory of Syntax. Cambridge: Cambridge University Press. UK.

[3] Crystal, David. (2003), English as a Global Language. (2 Ed), Cambridge University Press: UK.

[4] Daniel, D. (2013). Language Socialization and Language Teaching: An interview with Patricia (Patsy) Duff. Aichi Gakuin University.

[5] Fishman, J.A. (1997), The Sociology of Language in Sociolinguisitcs: A Reader and Course Book. London: Palgrane.

[6] Gumperz, J.J (1971), Language in social Groups. Stanford, $C A$ : Stanford University Press.

[7] Hornberger Nancy H., Dr. Sandra Lee McKay. (1996), Sociolinguistics and Language Teaching. Cambridge University Press: USA.

[8] Holmes, J. (1992), An Introduction to Sociolinguistics. London: Longman.

[9] Hudson, R.A. (1996). Sociolinguistics. Cambridge: Cambridge University Press.UK. 
[10] Jack, C, R. \& Richard, S (2002), Approaches and Methods in Language Teaching, (2 Ed). Cambridge University Press: UK.

[11] Keller, Helen. (2011), The Story of My Life. Ch IV. American Foundation for the Blind. www.afb.org/my life/book .asp?ch=P1ch 4 .

[12] Kramsch, Clarie. (1998), Language and Culture. Oxford University Press: New York.

[13] Nancy H. Hornberger and Sandra Lee MeKay. (2010), Sociolinguistics and Language Education. Multilingual Matters. Bristol.

[14] Miriam, Meyerhoff. (2006). Introducing Sociolinguistics. Routledge: Newyork.

[15] Samir K. Ghosh, Man, (1972), Language and Society: Contributions to the Sociology of Language. University of Michigan: Mouton.

[16] Saville-Troike. (2003), The Ethnography of Communication. Oxford: Blackwell.

[17] Trudgill, Peter. (2000), Sociolinguistics: An Introduction to Language and Society. England: Penguin Books.

[18] Vanpatten, Bill, Jessica Williams. (2014), Theories in Second Language Acquisition: An Introduction (2ed). Routledge, UK.

[19] Yule, George. (1996), The Study of Language, (2 ed). Cambridge University Press: UK 